\title{
Damage control in penetrating cardiac trauma
}

\section{El control de daños en el trauma cardíaco penetrante}

\author{
Adolfo González-Hadad ${ }^{1,2,3}$ (D) Carlos A. Ordoñez ${ }^{1,4,5}$ (D) Michael W. Parra ${ }^{6}$ (D) Yaset \\ Caicedo $^{7 \text { (D) Natalia Padilla }}{ }^{7}$ Mauricio Millán ${ }^{5,8}$ (D) Alberto García ${ }^{1,4,5}$ Jenny Marcela \\ Vidal-Carpio ${ }^{9,10}$ Luis Fernando Pino ${ }^{1,2}$ (D) Mario Alain Herrera ${ }^{1,2}$ (D) Laureano Quintero ${ }^{1,3}$ \\ Fabian Hernández ${ }^{1,2}$ Guillermo Flórez ${ }^{1}$ Fernando Rodríguez-Holguín ${ }^{4}$ Alexander \\ Salcedo ${ }^{1,2,4,5}$ (iD José Julián Serna ${ }^{1,2,4,5}$ (D) María Josefa Franco ${ }^{4}$ Ricardo Ferrada ${ }^{2,3}$ Pradeep \\ H. Navsaria ${ }^{11}$
}

ordonezcarlosa@gmail.com, carlos.ordonez@fvl.org.co

1 Universidad del Valle, Facultad de Salud, Escuela de Medicina, Department of Surgery, Division of Trauma and Acute Care Surgery. Cali, Colombia. 2 Hospital Universitario del Valle, Department of Surgery, Division of Trauma and Acute Care Surgery, Cali, Colombia. 3 Centro Médico Imbanaco, Cali, Colombia. 4 Fundación Valle del Lili, Department of Surgery, Division of Trauma and Acute Care Surgery, Cali, Colombia. 5 Universidad Icesi, Cali, Colombia. 6 Broward General Level I Trauma Center, Department of Trauma Critical Care, Fort Lauderdale, FL, USA, 7 Fundacion Valle del Lili, Centro de Investigaciones Clinicas (ClC), Cali, Colombia, 8 Fundación Valle del Lili, Department of Surgery, Division of Transplant Surgery, Cali, Colombia , 9 Hospital General Teofilo Davila, Servicio de Emergencias, Cuenca, Ecuador. 10 Universidad de Cuenca, Department of Surgery, Cuenca, Ecuador. 11 University of Cape Town, Faculty of Health Sciences, Groote Schuur Hospital, Trauma Center, Anzio Road, Observatory, Cape Town, South Africa

\section{Abstract}

Definitive management of hemodynamically stable patients with penetrating cardiac injuries remains controversial between those who propose aggressive invasive care versus those who opt for a less invasive or non-operative approach. This controversy even extends to cases of hemodynamically unstable patients in which damage control surgery is thought to be useful and effective. The aim of this article is to delineate our experience in the surgical management of penetrating cardiac injuries via the creation of a clear and practical algorithm that includes basic principles of damage control surgery. We recommend that all patients with precordial penetrating injuries undergo trans-thoracic ultrasound screening as an integral component of their initial evaluation. In those patients who arrive hemodynamically stable but have a positive ultrasound, a pericardial window with lavage and drainage should follow. We want to emphasize the importance of the pericardial lavage and drainage in the surgical management algorithm of these patients. Before this concept, all positive pericardial windows ended up in an open chest exploration. With the coming of the pericardial lavage and drainage procedure, the reported literature and our experience have shown that $25 \%$ of positive pericardial windows do not benefit and/or require further invasive procedures. However, in hemodynamically unstable patients, damage control surgery may still be required to control ongoing bleeding. For this purpose, we propose a surgical management algorithm that includes all of these essential clinical aspects in the care of these patients. 
Copyright: @ 2021 Universidad del Valle (c) (1) $(-)$

Conflicts of interest:

The authors declare that they have no conflict of interest.

\section{Acknowledgments:}

For the illustrations and the design of the cover to the Anatomical Draftsman Fabian R. Cabrera P. Professor of the Design, Department of Faculty of Integrated Arts of the Universidad del Valle

Corresponding author:

Carlos A. Ordonez, MD, FACS.

Division of Trauma and Acute Care Surgery, Department of Surgery.

Fundación Valle del Lili. Cali, Colombia; Division of Trauma and Acute Care Surgery, Department of Surgery, Universidad del Valle, Cali, Colombia; Universidad Icesi, Cali, Colombia.

e-mail: ordonezcarlosa@gmail. com, carlos.ordonez@fvl.org.co

\section{Resumen}

El manejo definitivo de los pacientes hemodinámicamente estables con heridas cardíacas penetrantes continúa siendo controversial con abordajes invasivos versus manejos conservadores. Estas posiciones contrarias se extienden hasta aquellos casos de pacientes hemodinámicamente inestables donde se ha descrito y considerado la cirugía de control de daños como un procedimiento útil y efectivo. El objetivo de este artículo es presentar la experiencia en el manejo quirúrgico de heridas cardíacas penetrantes con la creación de un algoritmo práctico que incluye los principios básicos del control de daños. Se recomienda que a todos los pacientes con heridas precordiales penetrantes se les debe realizar un ultrasonido torácico como componente integral de la evaluación inicial. Aquellos que presenten un ultrasonido torácico positivo y se encuentren hemodinámicamente estables se les debe realizar una ventana pericárdica con posterior lavado. Se ha demostrado que el $25 \%$ de las ventanas pericárdicas positivas no se benefician ni requieren de posteriores abordajes quirúrgicos invasivos. Antes de este concepto, todos los pacientes con ventana pericárdica positiva terminaban en una exploración abierta del tórax y del pericárdico.

Los pacientes hemodinámicamente inestables requieren de una cirugía de control de daños para un adecuado y oportuno control del sangrado. Con este propósito, se propone un algoritmo de manejo quirúrgico que incluye todos estos aspectos esenciales en el abordaje de este grupo de pacientes.

\section{Remark}

\section{1) Why was this study conducted?}

To delineate our experience in the surgical management of penetrating cardiac injuries via the creation of a clear and practical algorithm that includes basic principles of damage control surgery

\section{2) What were the most relevant results of the study?}

All patients with precordial penetrating injuries should undergo trans-thoracic ultrasound screening as an integral component of their initial evaluation. In those patients who arrive hemodynamically stable but have a positive ultrasound, a pericardial window with lavage and drainage should follow. However, in hemodynamically unstable patients, damage control surgerymay still be required to control ongoing bleeding

\section{3) What do these results contribute?}

We have developed a clinical algorithm that illustrates the five steps involved in the surgical management of patients with penetrating precordial injuries 


\section{Introduction}

Only $45 \%$ of patients with cardiac injuries arrive alive to a trauma center requiring a timely diagnosis and expeditious management ${ }^{1,2}$. Definitive management of hemodynamically stable penetrating cardiac injuries remains controversial between those who propose aggressive invasive care versus those who opt for a less invasive or non-operative approach. This controversy even extends to cases of hemodynamically unstable patients in which damage control surgery is thought to be useful and effective. The aim of this article is to delineate the experience obtained in the surgical management of penetrating cardiac injuries via the creation of a clear and practical algorithm that includes basic principles of damage control surgery.

This article is a consensus that synthesizes the experience earned during the past 30 years in trauma critical care management of the severely injured patient from the Trauma and Emergency Surgery Group (CTE) of Cali, Colombia which is made up of experts from the University Hospital del Valle "Evaristo García", the University Hospital Fundación Valle del Lili, the Universidad del Valle and Universidad Icesi, the Asociación Colombiana de Cirugía, the Pan-American Trauma Society and the collaboration of international specialists of the United States of America, Europe, Japan, South Africa, and Latin America.

\section{Epidemiology}

Approximately $20 \%$ of all patients who di'e from thoracic trauma do so from heart injury 3. Half of all cardiac injuries die at the scene and an additional 33\% die during initial transport or on arrival to the emergency room ${ }^{4}$. Of the patients who arrive alive to the hospital, $63 \%$ survive to discharge and in most cases the right ventricle is the injured chamber because it forms the majority of the anterior surface of the heart ${ }^{5,6}$. A series of 711 patients in the United States found that $54 \%$ of cardiac injuries were from stab wounds and $42 \%$ were from gunshot wounds. Complex injuries included coronary arteries and heart valves, one-third of the injuries were multiple and the overall mortality was $47 \%{ }^{7}$. In contrast, a study of 240 patients in Bogotá, Colombia, revealed that $93 \%$ of all penetrating cardiac injuries were by stab wound and $7 \%$ were by gunshot wounds. The overall mortality was $15 \%, 12 \%$ in the stab wounds group versus $41 \%$ in the gunshot wounds group. The distribution according to the American Association for the Surgery of Trauma (AAST) classification was 33\% Grade II, 13\% Grade

Table 1. The American Association for the Surgery of Trauma (AAST) Heart Injury Scale ${ }^{1}$ Grade Description

\begin{tabular}{|c|c|}
\hline \multirow[t]{2}{*}{ I } & $\begin{array}{l}\text { Blunt cardiac injury with minor ECG abnormality (nonspecific ST or T wave changes, premature atrial or ventricular con- } \\
\text { traction or persistent sinus tachycardia) }\end{array}$ \\
\hline & Blunt or penetrating pericardial wound without cardiac injury, cardiac tamponade, or cardiac herniation \\
\hline \multirow[t]{2}{*}{ II } & $\begin{array}{l}\text { Blunt cardiac injury with heart block (right or left bundle branch, left anterior fascicular, or atrioventricular) or ischemic } \\
\text { changes (ST depression or T wave inversion) without cardiac failure }\end{array}$ \\
\hline & Penetrating tangential myocardial wound up to, but not extending through endocardium, without tamponade \\
\hline \multirow{4}{*}{ III } & Blunt cardiac injury with sustained ( $>6$ beats/min) or multilocal ventricular contractions \\
\hline & $\begin{array}{l}\text { Blunt or penetrating cardiac injury with septal rupture, pulmonary or tricuspid valvular incompetence, papillary muscle } \\
\text { dysfunction, or distal coronary arterial occlusion without cardiac failure }\end{array}$ \\
\hline & Blunt pericardial laceration with cardiac herniation \\
\hline & Blunt cardiac injury with cardiac failure \\
\hline \multirow{7}{*}{ IV } & Penetrating tangential myocardial wound up to, but extending through, endocardium, with tamponade \\
\hline & $\begin{array}{l}\text { Blunt or penetrating cardiac injury with septal rupture, pulmonary or tricuspid valvular incompetence, papillary muscle } \\
\text { dysfunction, or distal coronary arterial occlusion producing cardiac failure }\end{array}$ \\
\hline & Blunt or penetrating cardiac injury with aortic mitral valve incompetence \\
\hline & Blunt or penetrating cardiac injury of the right ventricle, right atrium, or left atrium \\
\hline & Blunt or penetrating cardiac injury with proximal coronary arterial occlusion \\
\hline & Blunt or penetrating left ventricular perforation \\
\hline & Stellate wound with $<50 \%$ tissue loss of the right ventricle, right atrium, or of left atrium \\
\hline $\mathrm{V}$ & Blunt avulsion of the heart; penetrating wound producing $>50 \%$ tissue loss of a chamber \\
\hline
\end{tabular}


III, 29\% Grade IV and 25\% Grade V (Table 1). Upon arrival, 44\% were hemodynamically stable, $34 \%$ were in severe shock, $67 \%$ had signs of cardiac tamponade, and $18 \%$ were in extremis ${ }^{8}$. Similarly, the University Hospital del Valle experience from 2003 to 2004 revealed a total of 286 patients with penetrating precordial injuries. Twenty-nine percent arrived hemodynamically unstable and required emergency median sternotomy or left/anterolateral thoracotomy. Sixty-seven percent had a cardiac injury and $11 \%$ were negative. Hemodynamic stability was seen in $71 \%$ of patients upon admission and of these $4 \%$ (8 patients) underwent non-operative management and the remaining had a pericardial window which was positive in only $22 \%$ of cases ${ }^{4,6,9}$. Together these studies have determined the following risk factors that increase mortality in patients with penetrating cardiac injury: delay in transport and/or definitive treatment, shock, cardiac tamponade, gunshot wounds, multiple penetrating cardiac injuries and valve/septal/conduction system/major vessel involvement ${ }^{10,11}$.

\section{Initial Approach, Diagnosis and Surgical Management}

Initial management must be directed towards the stabilization of the patient according to Advanced Trauma Life Support (ATLS) ${ }^{\circledR}$ guidelines and following damage control resuscitation principles. Upon arrival, the choice between immediate surgical exploration or further imaging studies is dependent on the hemodynamic status of the patient. If the patient is hemodynamically stable or a transient responder, a thoracic ultrasound should be performed to determine the possibility of a cardiac injury, impending cardiac tamponade and/ or injury to any other associated adjacent structures. It is important to note that the classic clinical presentation of the Beck Triad (muffled heart sounds, jugular engorgement and hypotension) which is suggestive of cardiac tamponade occurs in less than $10 \%$ of confirmed cases. Regardless of its high specificity, the routine portable chest X-ray which makes part of the primary survey in ATLS has a very low sensitivity in diagnosing cardiac tamponade. For these reasons, the screening test of choice to determine whether a patient with a penetrating precordial injury has an impending cardiac tamponade is a thoracic ultrasound, which has a sensitivity of $79 \%$, a specificity of $92 \%$, and a negative predictive value of $95 \%{ }^{11}$. If the first thoracic ultrasound is negative and the patient remains hemodynamically stable, then a second thoracic ultrasound should be repeated in 6 hours. If the second thoracic ultrasound is also negative and the patient has no other associated injuries, then the patient can be discharged safely home.

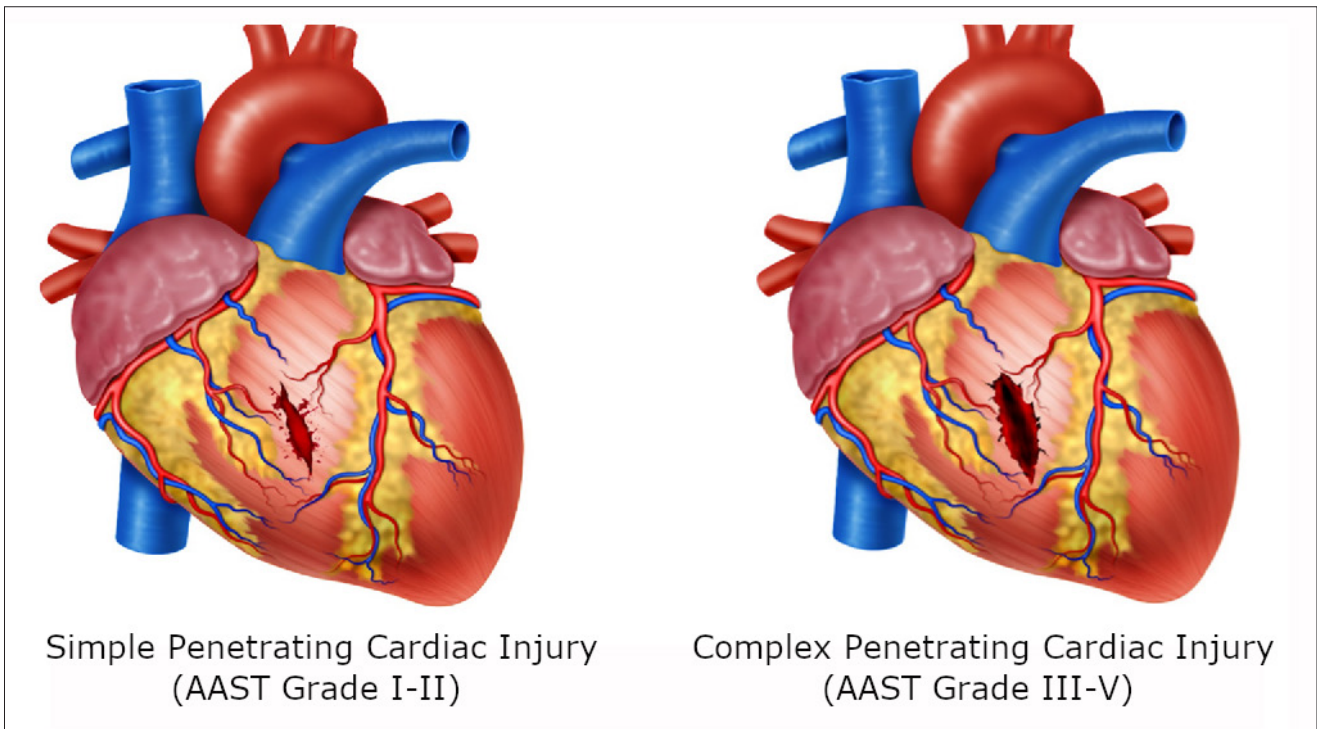

Figure 1. Cardiac Injuries. A. Cardiac injury of the ventricle with perilesional clot but not extending through the endocardium. B. Penetrating cardiac injury extending through the endocardium. 


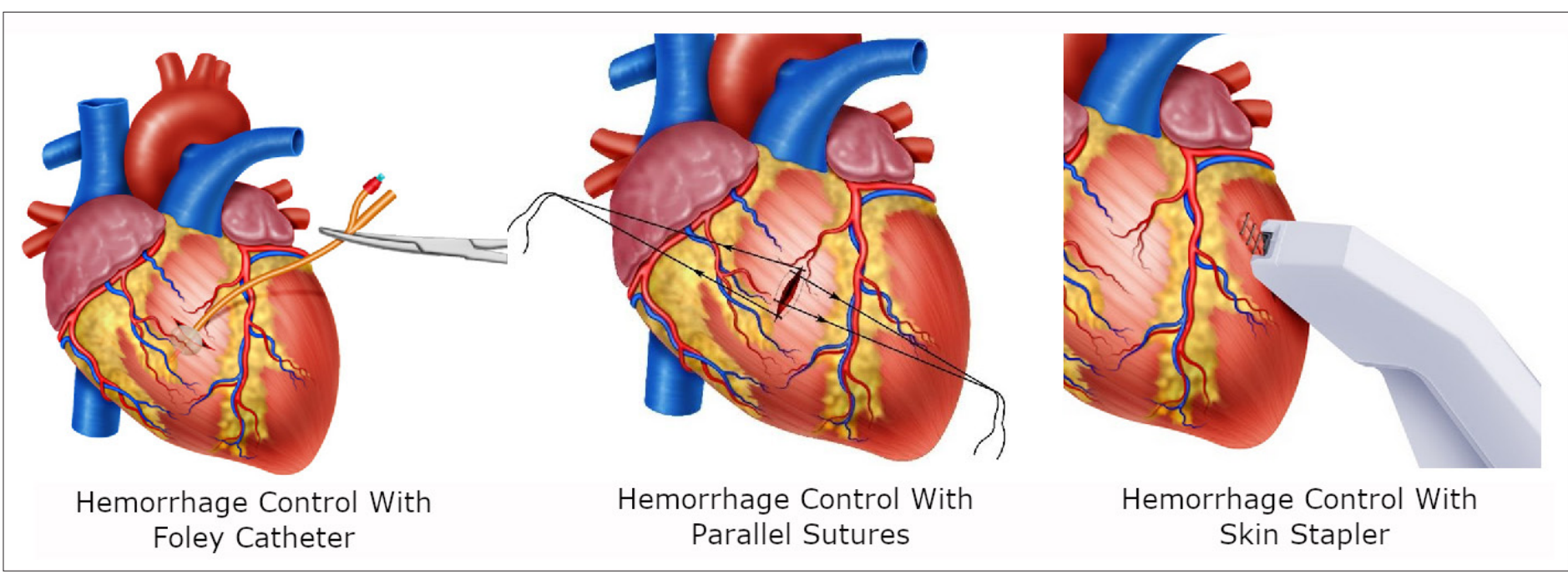

Figure 2. Damage control techniques in Cardiac Trauma. A. In cardiac injuries extending through the endocardium a Foley catheter should be inserted into the wound, inflated and gently retracted to achieve hemorrhage control. B. Hemorrhage control with sutures placed parallel to the wound then cross and/or tight. C. Temporal hemorrhage control with skin Stapler.

However, if the patient arrives hemodynamically unstable (sustained systolic blood pressure $<90 \mathrm{~mm} \mathrm{Hg}$ ) but not in cardiac arrest then attention should be directed towards identifying all life-threatening injuries and transferred immediately to the operating room for chest exploration via median sternotomy or antero-lateral thoracotomy. A median sternotomy provides better exposure to the mediastinal structures but it takes longer to get access when compared to an antero-lateral thoracotomy. As a general rule, if the injury is located between the nipples then the median sternotomy is more likely to provide better exposure. If the injury is located lateral to the nipples, then an antero-lateral thoracotomy (right/left) is preferred ${ }^{5}$.

If the patient arrives in cardiac arrest, then an immediate resuscitative left antero-lateral thoracotomy with cross-clamping of the aorta, longitudinal pericardiotomy and internal cardiac massage should be performed.

Based on our experience we propose a new algorithm for the management of penetrating precordial injuries:

- $\quad$ STEP 1: Attention should be directed towards identifying all immediate life-threatening injuries following the $\mathrm{ABC}$ mnemonic of ATLS, chest X-ray and thoracic ultrasound. An aggressive damage control resuscitation is initiated via the activation of the institution's massive transfusion protocol.

- STEP 2: All patients with hemodynamic instability, non-transient responders, cardiac tamponade and/or cardiac arrest should be transferred immediately to the operating room for chest exploration to obtain direct surgical control of the bleeding via a median sternotomy or left antero-lateral thoracotomy. The location and magnitude (Simple: AAST Grade I-II vs. Complex: AAST Grade III-V) of the cardiac injury should be determined as soon as possible ${ }^{12}($ Figure $1 \mathrm{~A} / 1 \mathrm{~B})$.

Transient control of ongoing surgical bleeding can be achieved by:

- Digital control: direct pressure with the surgeon's finger onto and not into the cardiac wound using his or her non-dominant hand is the best way to stop bleeding from the ventricles ${ }^{5}$. This maneuver may be aided by the use of a gauze.

- Foley catheter: If the heart wound cannot be controlled digitally then a Foley catheter should be inserted into the wound, inflated (5-10 cc) and gently retracted to achieve hemorrhage control (Figure 2A). 


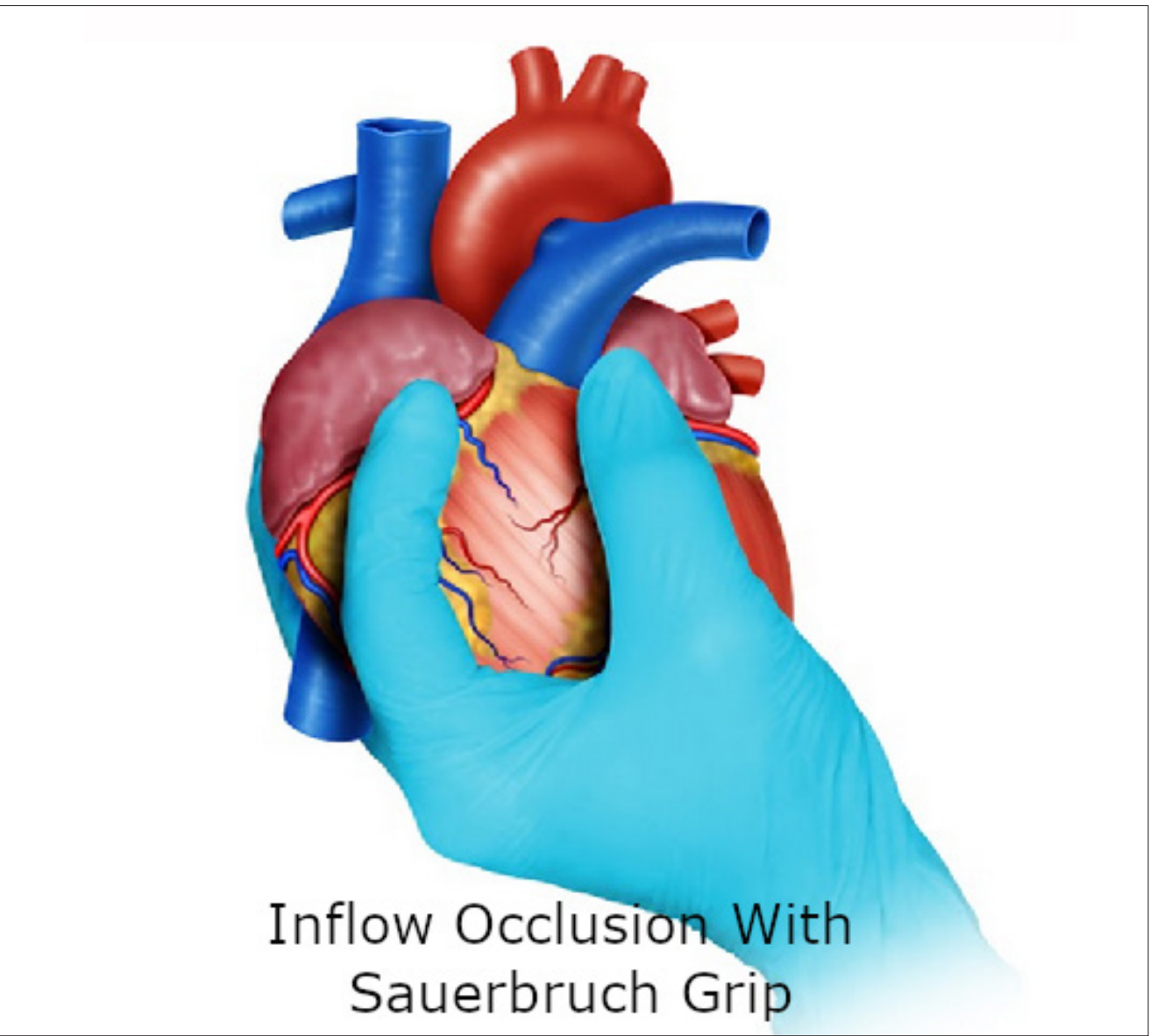

Figure 3. Damage control techniques in Cardiac Trauma. A. In cardiac injuries extending through the endocardium a Foley catheter should be inserted into the wound, inflated and gently retracted to achieve hemorrhage control. B. Hemorrhage control with sutures placed parallel to the wound then cross and/or tight. C. Temporal hemorrhage control with skin Stapler.

- Parallel Sutures: A suture should be placed parallel to the wound of either side and then cross and/or tight to control the bleeding ${ }^{5}$ (Figure $2 \mathrm{~B}$ ).

- Skin Stapler: May be used initially where there is no immediate specialized support but must be removed as soon as possible. The long-term outcome of leaving cardiac wounds stapled is unknown ${ }^{5}$ (Figure 2C).

- Sauerbruch Grip: If the hemorrhage is so severe that the surgeon is not able to visualize the source, then this grip should be applied to achieve total inflow occlusion by compressing the vena cava at the junction with the right atrium. To obtain this occlusion, the third finger of the surgeon is placed posteriorly to the vena cava and the second finger anteriorly, followed by interdigital compression ${ }^{5}$ (Figure 3 ). We must clarify that these temporizing techniques can be implemented individually or in combination to achieve hemorrhage control prior to definitive repair.

As soon as transient hemorrhage control is achieved, repair of the injury must be performed. The type of cardiac suture required depends on the size and location of the wound. It is important to approximate the cardiac wound edges during suturing under minimal tension with the aim of not strangulating the tissue as the cardiac muscle can tear quite easily. This may result in an even larger defect ${ }^{5}$.

- For ventricular wounds $<5 \mathrm{~mm}$ and in younger patients, we recommend interrupted U-stitches using 3-0 polypropylene without teflon pledgets (Figure 4A). 


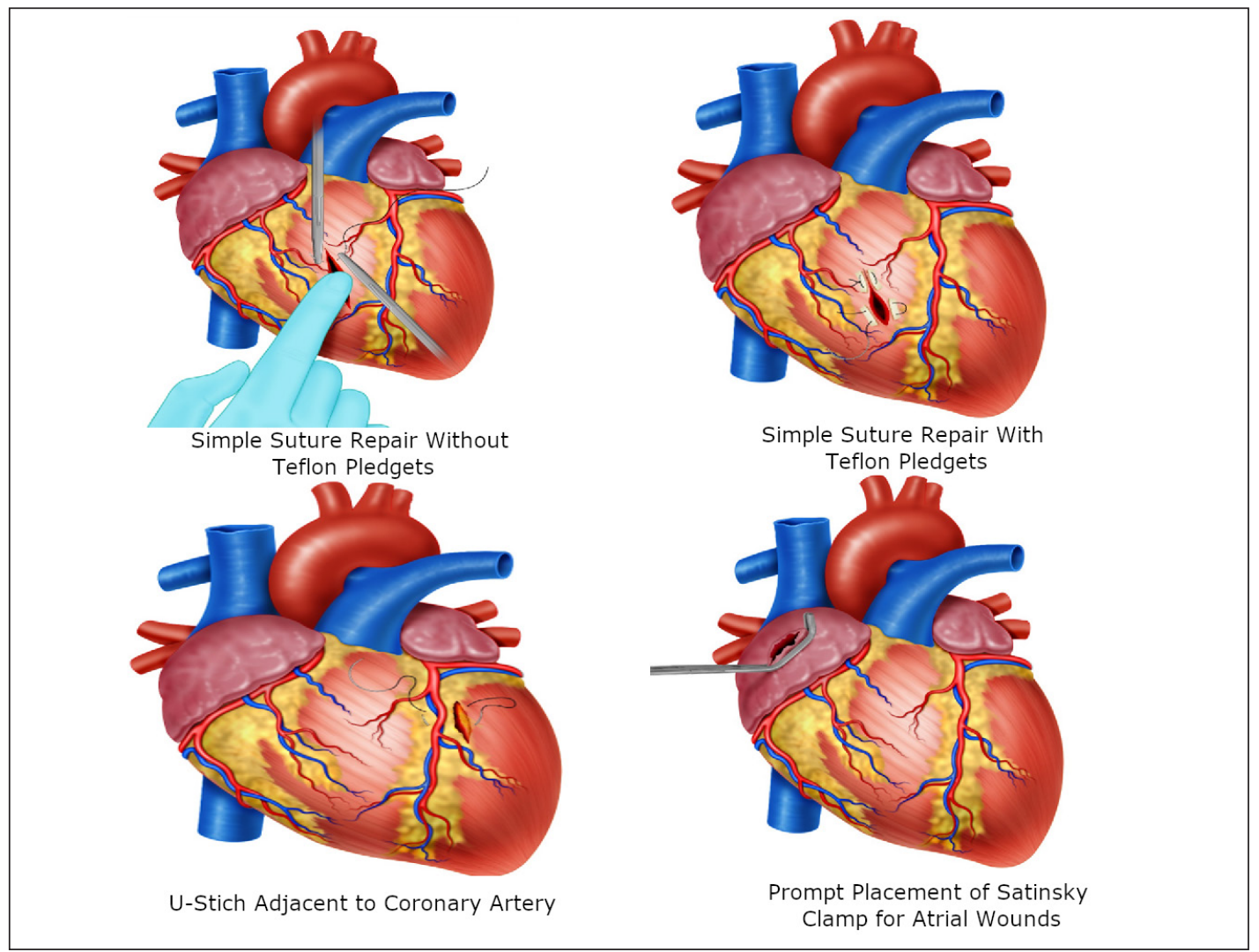

Figure 4. Surgical techniques in Cardiac Trauma A. Simple suture repair without Teflon pledgets in $<5 \mathrm{~mm}$ ventricular wounds. B. Simple suture repair with Teflon pledgets in older patients with $>5 \mathrm{~mm}$ ventricular wound. C. U-Stitch adjacent to a coronary artery. D. Prompt placement of a Satisnky Clamp for temporal hemorrhage control.

- For ventricular wounds $>5 \mathrm{~mm}$, older patients, evidence of cardiac dilatation and/or edema, we recommend $\mathrm{U}$-stitches with teflon pledgets (Figure 4B).

- For wounds adjacent to a coronary artery, we recommend U-stitches with teflon pledgets below the vessel to avoid iatrogenic injury. The suture should start adjacent to the coronary artery and the placement of the first bite should be directly under the vessel ${ }^{5}$ (Figure $4 \mathrm{C}$ ).

- For atrial wounds, we recommend prompt placement of a Satisnky clamp which facilitates the subsequent repair of the injury. If the first clamp is successful then place a second clamp slightly below the first and remove the initial one. This provides sufficient cardiac tissue for suturing of the injury with a continuous suture repair with 3-0 polypropylene. The Satinsky clamp should not be used in the ventricles as they are too thick-walled and the ventricle may be damage in the process ${ }^{5}$ (Figure $4 \mathrm{D} / / 5 \mathrm{~A}$ )

- For injuries $>2 \mathrm{~cm}$, the heart should be held together with the non-dominant hand of the surgeon and a continuous suture with 3-0 polypropylene performed. Hemostatic agents can be applied to the suture line to reassure hemostasis. If the suture line does not hold or the cardiac tissue surrounding the injury is too damaged and friable then immediate consultation with the cardiothoracic service should be requested and the patient placed on extracorporeal bypass for definitive repair (Figure 5B).

- For posterior cardiac injuries, a cardiac lift should be performed, although these injuries are rare, they should always be considered and ruled out by direct visual inspection ${ }^{5}$. This procedure should be performed carefully and quickly, informing the anesthesiologist of potential rhythm disorders, sudden drop in cardiac output or sudden cardiac arrest (Figure 5C). 


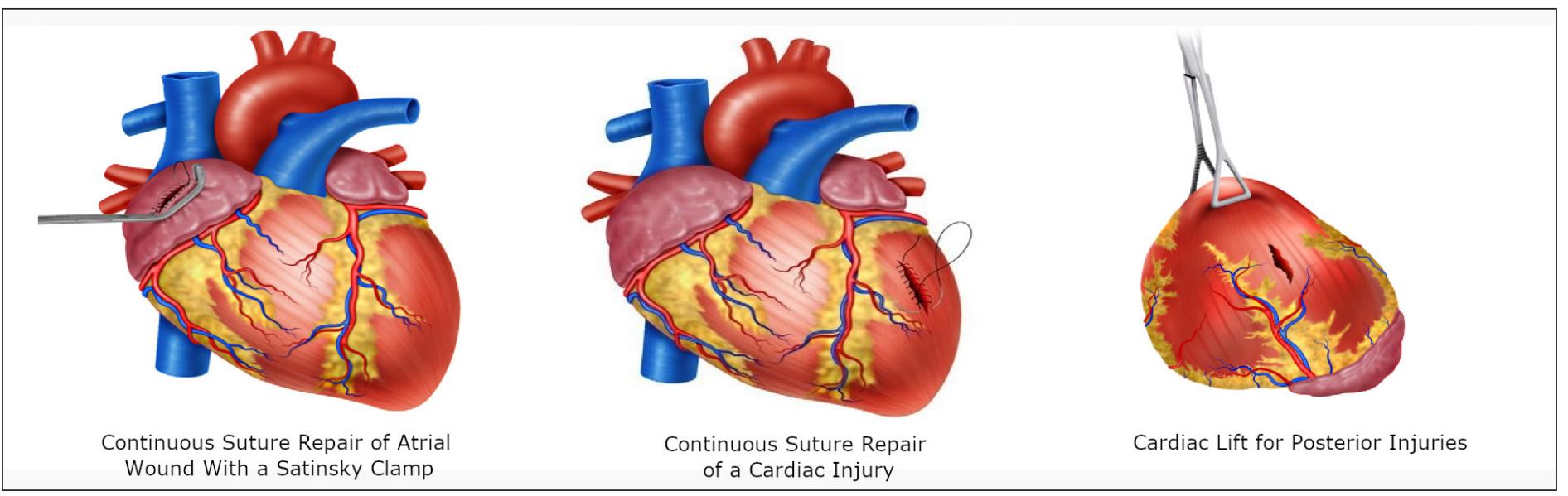

Figure 5. Surgical techniques in Cardiac Trauma. A. Continuous Suture Repair of Atrial Wound with a Satinsky clamp. B. Continuous suture repair of $>2 \mathrm{~cm}$ cardiac injury. C. Cardiac Lift for Posterior Injuries, which should be performed carefully and quickly due to potential rhythm disorders, sudden drop in cardiac output or sudden cardiac arrest.

After suturing the cardiac wound, careful hemostasis should be verified and damage control resuscitation continued. If bleeding persists then digital compression of the suture line with gauze and/or hemostatic agents should be applied. If the bleeding does not resolve then damage control surgery should be implemented by packing the heart and mediastinum, leaving the chest open and placing a negative pressure dressing. It is to note, the surgeon must verify that the pericardial sac is completely open to avoid potential cardiac herniation postoperatively. The patient should be transferred to the intensive care unit for lethal diamond correction ${ }^{13,14}$. In the intensive care unit, all patients with significant cardiac injuries should undergo a transthoracic or transesophageal echocardiogram within the first 6 hours after surgery to determine the coexistence of a septal injury and/or valve involvement. If this type of injury is confirmed, then consultation with the cardiovascular surgery service must follow. It is to note, that the majority of traumatic atrial/ventral septal defects close spontaneously over a period of 6 weeks and those that do not will require delayed repair ${ }^{5}$. Within 24 to 72 hours, damage control surgery patients should be taken back to the operating room for packing removal, mediastinal wash-out, re-evaluation of the cardiac injuries, mediastinal tube placement and definitive closure of the chest wall. It is recommended that this second procedure be done in conjunction with the cardiothoracic surgery team.

- STEP 3: Hemodynamically stable or transient responder patients should undergo thoracic ultrasound in the emergency room:

- If negative then a follow-up study should be done in 6 hours. If the second thoracic ultrasound is negative then the patient can be discharged safely home once other potential associated injuries have been ruled out or managed.

- If positive with a small hemopericardium $(<10 \mathrm{~mm})$ but without an associated hemothorax or signs of cardiac tamponade, the patient should undergo conservative nonoperative management via serial thoracic ultrasound at 6,12 and 24 hours in the intensive care unit. If follow-up thoracic ultrasound evolves to a moderate $(10-20 \mathrm{~mm})$ or a severe hemopericardium $(>20 \mathrm{~mm}$ ) and/or an associated significant hemothorax then the patient should be taken to the operating room immediately for a pericardial window.

- STEP 4: Patients with a positive thoracic ultrasound with a moderate to severe hemopericardium or an associated significant hemothorax and/or sign of cardiac tamponade, should proceed to a pericardial window to evaluate the presence of active surgical bleeding. The pericardial window should be done as follows:

- Sub-xiphoid pericardial window in patients with lesions of the precordial area without pleural involvement (no hemopneumothorax). 


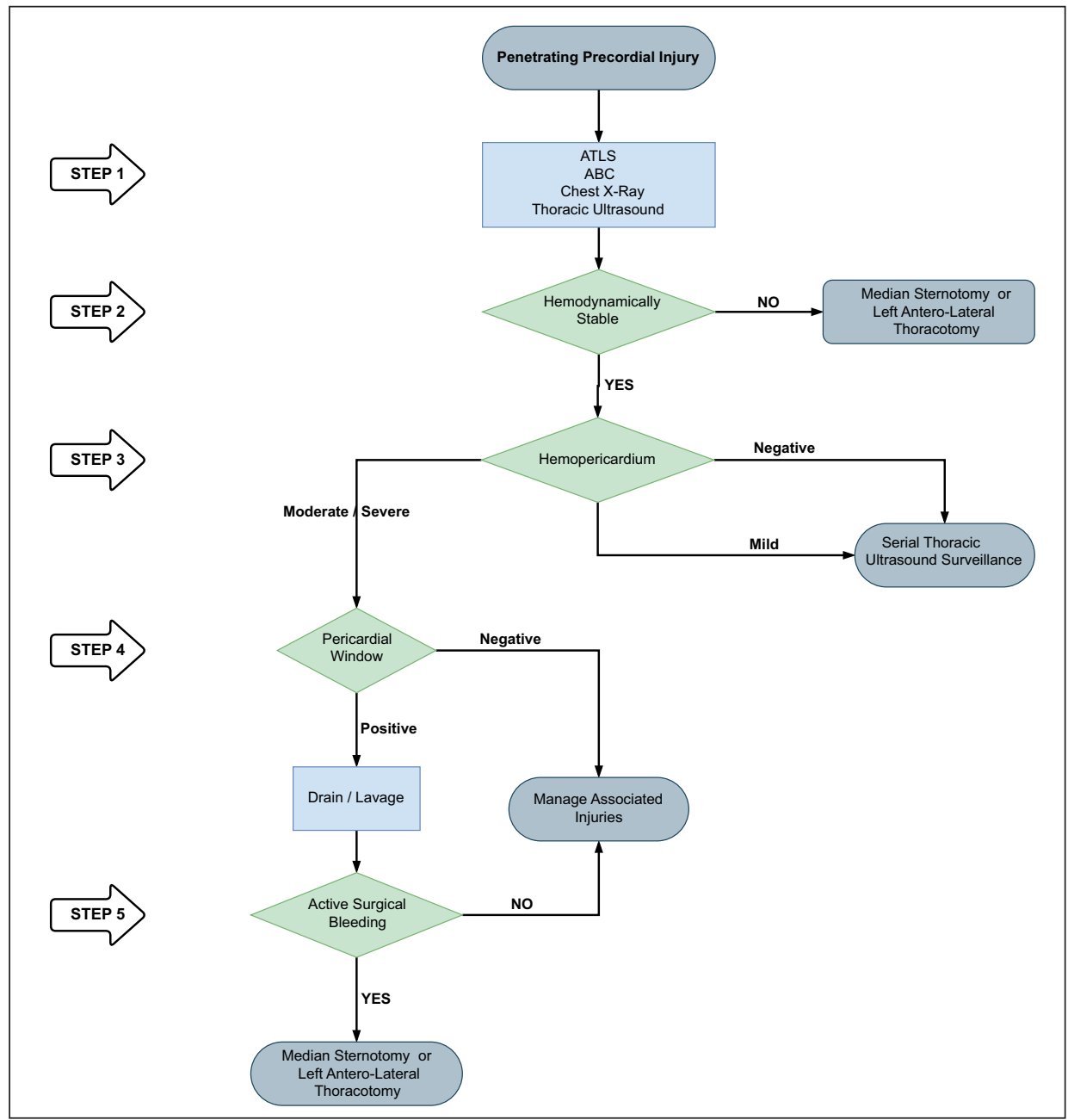

Figure 6. Surgical Management Algorithm for Penetrating Precordial Injuries

- Thoracoscopic pericardial window in those with lesions of the precordial area and pleural involvement evidenced by hemo and/or pneumothorax requiring chest tube placement.

- Laparoscopic pericardial window in those with injuries in the left thoraco-abdominal area with the aim of ruling out diaphragmatic or any other associated intra-abdominal solid or hollow viscus injuries.

- Transdiaphragmatic pericardial window in those with precordial area injuries and associated penetrating abdominal trauma requiring exploratory laparotomy.

- STEP 5: If the pericardial window is positive (blood and/or clots) then initial drainage and pericardial lavage with 500 to $1000 \mathrm{cc}$ of warm normal saline should be performed. If the pericardial lavage is negative, we recommend strict clinical monitoring in the intensive care unit and ruling out any other associated injuries. If the pericardial lavage is positive, then we recommend following STEP 2 to achieve control of all surgical bleeding.

We have developed a clinical algorithm that illustrates the five steps involved in the surgical management of patients with penetrating precordial injuries (Figure 6). 


\section{Complications}

Although infrequent, complications after operative and non-operative management of penetrating cardiac injuries are possible. Post-operative complications include mediastinal compartment syndrome and cardiac herniation or torsion; whereas non-operative complications include the development of delayed cardiac tamponade. The development of mediastinal compartment syndrome secondary to trauma is exceedingly rare. This phenomenon occurs when the median sternotomy incision is prematurely closed, precipitating an immediate elevation in the airway pressure and rapid hemodynamic collapse of the patient. This pathology requires an immediate reopening of the chest and installment of damage control surgery techniques with subsequent negative pressure dressing placement ${ }^{15}$. Iatrogenic cardiac herniation and torsion can occur after lateral pericardiotomy incisions that are left open, the signs and symptoms include: arrhythmia, myocardial ischemia and hypotension. This complication can be treated effectively via primary repair of the pericardial defect with sutures or placement of an autologous or synthetic patch ${ }^{16}$.

Delayed cardiac tamponade is a rare entity that is thought to be caused by: displacement of the initial thrombus that temporarily closes the cardiac wound, tearing of the initial injury due to adhesions and effusions due to post-cardiac injury syndrome. This complication can be identified by the systematic use of a transthoracic ultrasound, as it is an accurate and sensitive tool to detect hemopericardium, hemothorax and/or pneumopericardium. The presence of these associated findings can potentially lead to high rates of false-negative results, and to decrease them, it is our recommendation to perform serial in-hospital and out-patient clinical reassessments and follow-up ultrasounds (24 hours post-admission, 1 week, 1-month and 6-months). When a delayed cardiac tamponade does emerge the management of choice is a subxiphoid pericardial window with excellent results and low morbidity. All penetrating cardiac injury patients managed operatively or non-operatively should undergo close inhospital and out-patient follow-up with detailed instructions to identify early symptoms of chest pain and/or dyspnea as they are hallmarks signs of developing delayed complications ${ }^{17,18}$.

\section{Discussion}

The management of patients with penetrating precordial trauma remains controversial. During the 1990s, the only effective diagnostic tool of the time was the pericardial window which has a sensitivity of $97 \%$ and a specificity of $95 \%$ in detecting cardiac injury ${ }^{6,19}$. However, a major disadvantage is its invasiveness. Currently, the test of choice is a thoracic ultrasound that has gained traction and has been implemented in most trauma management guidelines around the world. Although it also has its inherent limitations which include operator dependency and equipment availability ${ }^{20,21}$. Feliciano et al studied a total of 228 hemodynamically stable patients with penetrating cardiac injuries and found 5 false-negative cases by thoracic ultrasound, two of which died secondary to delayed diagnosis ${ }^{22}$. Similarly, Nicol et al reviewed 172 cases of penetrating cardiac injury and found 18 cases of false-negatives, of which one required surgical intervention for impending cardiac tamponade ${ }^{21}$. In a study performed at our institution between 2016-2017, all precordial penetrating cardiac injuries underwent thoracic ultrasound followed by pericardial window when positive (subxiphoid $40 \%$, thoracoscopic $30 \%$ and laparoscopy/laparotomy $30 \%$ ). Pericardial window was able to determine that $74 \%$ of thoracic ultrasound were truly positive revealing an overall sensitivity of $79 \%$, a specificity of $93 \%$ and a negative predictive value of $95 \%$. Our thoracic ultrasound had an area under the curve of $0.86,95 \%$ CI: $0.78-0.93$, only $4 \%$ of cases were false-negatives, all had a coexisting hemothorax and none of them died ${ }^{11}$.

Chestovich et al found that only $24 \%$ of patients with positive pericardial windows were truly negative upon thorough pericardial lavage and the remaining $76 \%$ required median sternotomy due to ongoing surgical bleeding following lavage. A mediastinal drain was placed in all cases and subsequently transferred to the intensive care unit for further care. There were 
no significant differences among both groups according to morbidity and mortality ${ }^{23}$. Nicol et al also performed a clinical trial comparing 55 patients with positive pericardial windows who had follow-up median sternotomies versus 56 patients who had positive pericardial windows managed simply with pericardial drainage and warm saline lavage without chest opening. There was no significant difference in the rate of complications or clinical outcomes among groups ${ }^{24,25}$. With these findings, we recommend that hemodynamically stable penetrating precordial injured patients with positive thoracic ultrasound should undergo a pericardial window. If positive, the patient should undergo lavage. If there is no ongoing bleeding after lavage, the pericardium is drained and the patient monitored in the intensive care unit. But if there is ongoing bleeding, then the patient should undergo median sternotomy or anterolateral left thoracotomy for surgical control.

\section{Conclusion}

It is our recommendation that all patients with precordial penetrating injuries should undergo trans-thoracic ultrasound screening as an integral component of their initial evaluation. In those patients who arrive hemodynamically stable but have a positive ultrasound, a pericardial window with lavage and drainage should follow. We want to emphasize the importance of the pericardial lavage and drainage in the surgical management algorithm of these patients. Before this concept, all positive pericardial windows ended up in an open chest exploration. With the coming of the pericardial lavage and drainage procedure, the reported literature and our experience have shown that $25 \%$ of positive pericardial windows do not benefit and/or require further invasive procedures. However, in hemodynamically unstable patients, damage control surgery may still be required to control ongoing bleeding. For this purpose, we propose a surgical management algorithm that includes all of these essential clinical aspects in the care of these patients.

\section{References}

1. Morse BC, Mina MJ, Carr JS, Jhunjhunwala R, Dente CJ, Zink JU, et al. Penetrating cardiac injuries: A 36year perspective at an urban, Level i trauma center. J Trauma Acute Care Surg. 2016;81:623-31. doi: 10.1097/ TA.0000000000001165.

2. Degiannis E, Bowley DM, Westaby S. Penetrating cardiac injury. Ann R Coll Surg Engl. 2005;87:61-3. doi: $10.1308 / 1478708051207$.

3. Mugala DD, Makupe A, Ziddulla, Sakala D, Simon M, Chibale B, et al. Occurrence of penetrating chest and hearts injury following assaults: a presentation of two cases. MOJ Clin Med Case Reports. 2018;8:88-94. doi: 10.15406/mojcr.2018.08.00247. 4. Andrade-Alegre R. Trauma Cardíaco Penetrante. Panam J Trauma 2004;11:50-8. doi: 10.1017/
CBO9781107415324.004.

5. Nicol AJ. Cardiac Hemorrhage: Treatment of the Bleeding Heart. In: Ball CG, Dixon E, editors. Treatment of Ongoing Hemorrhage: The Art and Craft of Stopping Severe Bleeding. Springer; 2018, p. 67-80.

6. Sanchez AI, Garcia A, Velazquez M, Puyana JC. Predictors of positive subxiphoid pericardial window in stable patients with penetrating injuries to the precordial region. Panam J Trauma. 2016;5:43-51. doi: 10.5005/ jp-journals-10030-1142.

7. Wall MJ, Mattox KL, Chen CD, Baldwin JC. Acute management of complex cardiac injuries. J Trauma. 1997; 42: 905-12. doi: 10.1097/00005373-199705000-00022.

8. Isaza-Restrepo A, Bolívar-Sáenz DJ, Tarazona-Lara M, Tovar JR. Penetrating cardiac trauma: Analysis of 240 cases from a hospital in Bogota, Colombia. World J Emerg Surg. 2017;12:26. doi: 10.1186/s13017-017-0138-1. 
9. García A. Enfoque inicial del paciente estable con trauma precordial penetrante: ¿es tiempo de un cambio? Rev Colomb Cirugía. 2019;34:16-24. doi: 10.30944/20117582.93.

10. Ingraham A, Sperry J. Operative Management of Cardiac Injuries: Diagnosis, Technique, and Postoperative Complications. Curr Trauma Reports. 2015;1:225-31. doi: 10.1007/s40719-015-0032-9.

11. Gonzalez-Hadad A, García AF, Serna JJ, Herrera MA, Morales M, Manzano-Nunez R. The Role of Ultrasound for Detecting Occult Penetrating Cardiac Wounds in Hemodynamically Stable Patients. World J Surg. 2020;44:1673-80. doi: 10.1007/s00268-020-05376-7.

12. Moore EE, Malangoni MA, Cogbill TH, Shackford SR, Champion HR, Jurkovich GJ, et al. Organ injury scaling. IV: Thoracic vascular, lung, cardiac, and diaphragm. J Trauma. 1994;36:299-300.

13. Ditzel RM, Anderson JL, Eisenhart WJ, Rankin CJ, DeFeo DR, Oak S, et al. A review of transfusion- And trauma-induced hypocalcemia: Is it time to change the lethal triad to the lethal diamond? J Trauma Acute Care Surg. 2020;88:434-9. doi: 10.1097/TA.0000000000002570.

14. Ordoñez CA, Parra MW, Serna JJ, Rodríguez H F, García AF, Salcedo A, et al. Damage Control Resuscitation : REBOA as the New Fourth pillar. Colomb Med (Cali). 2020; 51(4): e4014353. doi: 10.25100/ cm.v51i4.4353.

15. Wandling MW, An GC. A case report of thoracic compartment syndrome in the setting of penetrating chest trauma and review of the literature. World J Emerg Surg. 2010;5:1-5. doi: 10.1186/1749-7922-5-22.

16. Onem G, Baltalarli A, Sungurtekin H, Evrengul H, Ozcan AV, Kaya S, et al. latrogenic cardiac herniation and torsion after surgery for a penetrating cardiac injury. Texas Hear Inst J. 2006;33:526-8.

17. Rendón F, Gómez Danés LH, Castro M. Delayed cardiac tamponade after penetrating thoracic trauma. Asian Cardiovasc Thorac Ann. 2004;12:139-42. doi: 10.1177/021849230401200212.

18. Van Waes OJF, Halm JA, Van Imhoff DI, Navsaria PH, Nicol AJ, Verhofstad MHJ, et al. Selective non-operative management of penetrating thoracic injury. Eur J Emerg Med. 2018;25:32-8. doi: 10.1097/ MEJ.0000000000000401.

19. Brewster SA, Thirlby RC, Snyder WH. Subxiphoid Pericardial Window and Penetrating Cardiac Trauma. Arch Surg. 1988;123:937-41. doi: 10.1001/archsurg.1988.01400320023003.

20. Saranteas T, Mavrogenis AF, Mandila C, Poularas J, Panou F. Ultrasound in cardiac trauma. J Crit Care. 2017;38:144-51. doi: 10.1016/j.jcrc.2016.10.032.

21. Nicol AJ, Navsaria PH, Beningfield S, Hommes M, Kahn D. Screening for occult penetrating cardiac injuries. Ann Surg. 2015;261:573-8. doi: 10.1097/SLA.0000000000000713.

22. Ball CG, Williams BH, Wyrzykowski AD, Nicholas JM, Rozycki GS, Feliciano D V. A caveat to the performance of pericardial ultrasound in patients with penetrating cardiac wounds. J Trauma. 2009;67:1123-4. doi: 10.1097/TA.0b013e3181b16f30.

23. Chestovich PJ, McNicoll CF, Fraser DR, Patel PP, Kuhls DA, Clark E, et al. Selective use of pericardial window and drainage as sole treatment for hemopericardium from penetrating chest trauma. Trauma Surg Acute Care Open. 2018;3:e000187. doi: 10.1136/tsaco-2018-000187.

24. Nicol AJ, Navsaria P, Hommes M, Ball C, Edu S, Kahn D. Sternotomy or Drainage for a Hemopericardium After Penetrating Trauma: A Safe Procedure? Ann Surg. 2016;263:e32. doi: 10.1097/SLA.0000000000001146.

25. Nicol AJ, Navsaria PH, Hommes M, Ball CG, Edu S, Kahn D. Sternotomy or drainage for a hemopericardium after penetrating trauma: A randomized controlled trial. Ann Surg. 2014;259:438-42. doi: 10.1097/SLA.0b013e31829069a1. 